CIUDAD Y TERRITORIO

ESTUDIOS TERRITORIALES

ISSN(P): 1133-4762; ISSN(E): 2659-3254

Vol. LII, № 204, verano 2020

Págs. 197-210

https://doi.org/10.37230/CyTET.2020.204.01

CC BY-NC 4.0

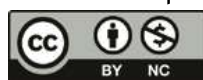

\title{
Notas sobre la obsolescencia de los planes generales: planificación estratégica y modelo urbano
}

\author{
Juan Antonio LoBATo-BeCERRA
}

Arquitecto y Sociólogo Territorio y Ciudad SLP

RESUMEN: La disciplina encargada (históricamente) de establecer una operativa para la toma de decisiones relativas al modelo de ordenación urbano territorial de nuestras ciudades, la urbanística, trata de afrontar la crisis, ya sistémica, de su herramienta metodológica por excelencia, el Plan General de Ordenación Urbanística (PGOU). El cambio del paradigma basado en la cultura de plan y en la ortodoxia reglamentaria hacia procedimientos heterodoxos -principalmente fundamentados en la singularidad del proyecto y en su articulación mediante mecanismos de gestión estratégica- está configurando un nuevo tipo de urbanismo, limitado territorialmente y condicionado temporalmente (como consecuencia de la propia escala y programación que este tipo de intervenciones -parciales- sobre lo urbano, supone), un urbanismo "miope", que no alcanza a tener una visión global de largo alcance del modelo que la ciudad debe pretender para su futuro. El presente estudio analiza el estado actual del planeamiento urbanístico municipal, comprobando el impacto que este cambio de paradigma ha tenido, y tiene, en el mismo y por ende en los modelos urbanos que subyacen y se derivan de aquel, certificándose, a tenor de los resultados obtenidos, su eminente -ya dramática- obsolescencia.

PALABRAS CLAVE: Planeamiento urbanístico; Plan General; Proyecto Urbano; Plan Estratégico.

\section{Notes on the obsolescence of general land use plans: strategic planning and urban model}

ABSTRACT: The discipline in charge (historically) of establishing an operative for decision making regarding the model of territorial urban planning of our cities, urban planning, tries to confront the crisis, already systemic, of its methodological tool par excellence, the land use general plan. The paradigm shift

Recibido: 19.11.2018; Revisado: 22.06.2019

Correo electrónico: lobato@territorioyciudad.com No ORCID: https://orcid.org/0000-0002-0517-0135

El autor agradece los comentarios y sugerencias realizados por los evaluadores anónimos, que han contribuido a mejorar y enriquecer el manuscrito original. 
based on the culture of plan and regulatory orthodoxy towards heterodox procedures -mainly based on the project's uniqueness and its articulation through strategic management- is configuring a new type of urbanism, limited territorially and conditioned temporarily (as a consequence of the scale and programming that this type of interventions -partial- on the urban supposes), a "myopic" urbanism, which does not manage to have a global vision of long range of the urban model that the city must pretend for its future. The present study analyzes the current state of municipal urban planning, proving the impact that this paradigm shift has had, and has, on it and therefore on the urban models that underlie and derive from it, certifying, according to the results obtained, its eminent -already dramatic- obsolescence.

KEYWORDS: Urban planning; Urban Land Use Plan; Urban Project; Strategic Plan.

\section{Introducción}

- hábitat natural sobre el que construimos desde hace milenios nuestras comunidades, eso que (aún) llamamos ciudad vive un momento crucial para su propio devenir.

\begin{abstract}
"Mantener los niveles de consumo que exige la vida urbana moderna y, al mismo tiempo, contrarrestar las enormes fuerzas de disgregación que surgen en su crecimiento incontrolado requiere de una organización social con poderes tan vastos que escapan a cualquier noción de comunidad que hayamos conocido. $Y$ la comunidad, los bienes comunales y el municipio no solo están ligados etimológicamente, sino que han supuesto, durante milenios el hábitat natural sobre el que se construyen todo tipo de sociedades. La posibilidad de vida en la ciudad desaparece cuando desaparece ese hábitat". (Agulles, 2017:29).
\end{abstract}

Son tantos los desafíos y los retos que se plantean, los problemas y disfuncionalidades que se constatan que la simple tarea de su abordaje sistemático se antoja cuanto menos difícil de alcanzar.

"En todo caso, la solución no es renegar de la ciudad e imaginar una imposible nueva realidad bucólico-pastoril (inviable y, además, tan pervertible como la actual situación urbana). La solución es supeditar las actuaciones personales a una ética de interés colectivo e implementar, eso sí, una buena política socioecológica..." (FoLCH, 2017).

El abordaje sistemático para la intervención, diseño y conformación de las ciudades queda asentado en España, después de una serie de avatares históricos (primeras leyes decimonónicas de ensanche y reforma, y ya en tiempos de Primo de Rivera, los reglamentos del estatuto municipal de Calvo Sotelo de 1924) con la aprobación de la Ley del Suelo y valoraciones de 1956, en la que se otorga al planeamiento general el papel principal en la configuración de lo urbano, disponiéndose en el propio Reglamento de Planeamiento que la ordenación urbanística deba ser llevada a cabo por el Plan General Municipal de Ordenación Urbana.

"El modelo territorial por el que, con más o menos aciertos, pero democráticamente, los municipios apuesten y que recoge objetivos territoriales y legislativos de escalas superiores (Ordenación del Territorio, legislación urbanística específica y legislaciones sectoriales) se compendia en los planes urbanísticos... Entre estos destaca como principal instrumento de planeamiento urbanístico el Plan General de Ordenación Urbanística (PGOU). A su vez, este planeamiento general se desarrolla mediante un Planeamiento de desarroIlo (Planes Parciales, Planes Especiales y Estudios de Detalles), que se circunscriben a espacios concretos del suelo urbano y/o urbanizable. Por tanto, el objetivo del PGOU es también integral, ordenando territorial y urbanísticamente todo el municipio." (JURADO, 2010: 282)

Este instrumento es el encargado de establecer los elementos fundamentales de la estructura general adoptada por la ordenación urbanística para un territorio, clasificar el suelo para determinar el régimen jurídico atribuido al mismo, así como programar el desarrollo y ejecución de sus objetivos en un plazo temporal establecido, definiendo así lo que ya desde la Ley del 76 se dispone como "modelo" territorial y es que,

"Todo desarrollo urbano se materializa en un programa de obras, pero solo se construye la ciudad futura de manera equilibrada si dicho programa de obras responde a un proyecto global que sea expresión de la voluntad colectiva de todos los ciudadanos. Y ese proyecto no es otro que el PGOU." (GoNZÁlez, 2009).

El Plan General determina para la consecución de los objetivos que se derivan de su modelo de ordenación la intervención en una serie de ámbitos cuya ordenación final deberá ser establecida por toda una serie de instrumentos urbanísticos (planes parciales, planes especiales, de reforma interior $y / o$ estudios de detalle...) 
que implementarán el proyecto definitorio que desarrolle los mismos.

Si bien la validez de esta jerarquía metodológica parece, en teoría, muy clara, la realidad fáctica de los hechos evidencia, ya desde estos orígenes, una práctica contraria, siguiendo el Plan General la iniciativa o iniciativas de determinados proyectos singulares para la ciudad, sin que exista o respete un modelo de ciudad consensuado y establecido por el propio plan general.

“... Es cierto que al perder el planeamiento general posterior a 1940/50 el nivel de detalle que había caracterizado a los proyectos de ensanche y extensión de las ocho décadas anteriores, se está perdiendo claridad y precisión en la imagen propuesta para la nueva ciudad. Pero no es menos cierto que la aproximación procesual a la forma urbana, a través de los Planes Generales desarrollados por Planes Parciales y por proyectos de arquitectura, es una metodología válida si se establecen los mecanismos que aseguren la calidad y coordinación de los distintos momentos proyectuales." (LÓPEZ DE LUCIO, 1993: 65).

Esta sistemática fue la integrada en la mayoría de procesos de regeneración urbana de grandes ciudades europeas -con gran efusividad- a partir de la década de los ochenta (FERNÁNDEZ-Ges, 2018: 134), y es que el debate entre plan y proyecto $^{1}$, no ha dejado de ser recurrente en la práctica urbanística, teniendo como en toda contienda detractores a un lado y partidarios a otro. En España, la "escuela" catalana abanderada por Manuel de Solà-Morales realiza, en la década de los ochenta, una crítica feroz al plan general por su magnitud e inoperatividad (SAINZ, 2006: 132) mientras que ya en épocas más recientes se cuestiona la idoneidad del proyecto urbano (CAPEL, 2005; MolinA, 2017). Tampoco han faltado las teorías de fusión entre ambas entidades, los proyectos de tercera generación o planes-proyecto (PORTAS, 2003: 2) en defensa de una regulación variable en armonía con la programación del plan y la oportunidad de la estrategia. La irrupción de procedimientos de gestión estratégica en la planificación de las ciudades también ha supuesto una gran incidencia en los métodos para el diseño de su modelo urbano $^{2}$, derivándose de todo ello, también, un gran debate. De hecho, viene observándose en épocas más recientes un giro hacia la gestión estratégica de este tipo de intervenciones.

1 Un profundo e interesantísimo relato pormenorizado de dicho debate se ofrece en el manuscrito del gran maestro urbanista Fernando de TERÁN Antes de salir por la puerta del tiempo (2017). 2 De la amplia bibliografía relativa a este respecto, deben destacarse dos fuentes por su estrecha vinculación con el presente
Diferentes motivaciones han provocado este giro metodológico que ha supuesto el reemplazo del planeamiento general por otro tipo de instrumentos: quizás la primacía del interés particular (del operador que desarrolla el proyecto urbano) sobre el interés general sea la más notoria, pero también la decisión política de apostar por el camino singular y particular -en apariencia- más corto y alcanzable en lugar de abordar la singladura que la solución a la problemática plural y general supone, máxime en situaciones de incertidumbre y crisis económica.

Todo ello, no cabe duda, ha tenido, y tiene, una gran repercusión en el valor que, como herramienta de gestión municipal, se le asigna al planeamiento general, de tal suerte que la producción del mismo en todo el territorio nacional ha caído en picado, cercado por un halo de desconfianza y descrédito. El propio Libro blanco de la Sostenibilidad en el Planeamiento Urbanístico Español viene a reflejar esta circunstancia que ahonda en la progresiva pérdida de confianza de este tipo de urbanismo más científico y su sustitución por la aplicación de catálogos de buenas prácticas y proyectos singulares.

“... Además, el plan general es un instrumento sumamente pesado y casi imposible de modificar sobre todo en ciudades grandes. De forma que la mayor parte de las ciudades españolas se están limitando a mantener sus planes generales, normalmente muy antiguos, y funcionan mediante modificaciones puntuales de planeamiento. Estas modificaciones puntuales de planeamiento en muchas ocasiones son tan importantes que cambian de forma determinante la imagen planteada en el plan sin tener en consideración las implicaciones que puedan incidir sobre el resto de la ciudad y su área de influencia. Esta situación, tanto en la planificación territorial como del planeamiento urbanístico, está sometiendo a una parálisis la ordenación racional de nuestros territorios que se están organizando y construyendo en función de intereses más particulares que colectivos." (Libro Blanco de la sostenibilidad en el planeamiento urbanístico español, D.G. DE ARQUITECTURA, VIVIENDA y SUeLo 2010: 27).

Cabe señalar que si bien es cierto que el planeamiento general no ha conseguido constituirse como la herramienta operativa para el desarrollo del modelo de ciudad perseguido que debe ser a lo largo de nuestra historia contemporánea ${ }^{3}$, la tónica de los últimos años, donde se han aprobado

artículo: El auge de los planes estratégicos y los proyectos urbanos. Hacia un planeamiento urbanístico consensuado (CRUz, 2008) y Nuevos Paradigmas y proyectos urbanos estratégicos, en Visiones Urbanas. De la cultura del plan al urbanismo paisajístico (DiEZ, Monclús: 2017). 
menos planes generales por año que en todo el periodo constitucional, viene a escenificar una situación con tintes de drama. El camino que se ha elegido para el establecimiento de muchos de los modelos de ciudades españolas ha sido liderado por la apuesta de proyectos urbanos integrados a su vez en procesos de planificación estratégica a los que se asigna el papel de suplantador/es del planeamiento general. Un subterfugio que "esquiva" la necesidad de la generación de un modelo urbano territorial nuevo o la revisión del mismo que supondría la aprobación de un nuevo plan general y que supone dar la espalda al asunto común para el bienestar de la población concernida que supone la función de la ordenación urbanística (PAREJo, 2017: 304). La ausencia de un marco regulador o la obsolescencia de este, se traduce en una falta de soporte técnico válido para el establecimiento de un modelo urbanístico sostenible, circunstancia que acaba pagando el territorio.

\begin{abstract}
“... Por tanto, cuando se "desdibuja" la función de los instrumentos reguladores, como el planeamiento, y éste no ejerce de soporte planificado de las políticas ejercidas a través de instrumentos aparece también la crisis de lo urbano, por la falta de correspondencia del cuerpo físico y las necesidades económicas y sociales. Existe una contradicción entre ambas esferas" (DELGADO, 2014).
\end{abstract}

El presente artículo tiene como objeto evidenciar la situación de quiebra técnica (aguda y sistémica) por la que atraviesa el planeamiento urbanístico municipal, justificada en el acusado descenso experimentado en los últimos años en la producción de planes generales, mostrando la incidencia que tiene el cambio del paradigma metodológico basado en la cultura de plan y en la ortodoxia reglamentaria hacia procedimientos heterodoxos basados en la singularidad del proyecto urbano articulado mediante mecanismos de gestión estratégica. Se pretende visualizar la magnitud de esta crisis, analizándose para ello la evolución del número de aprobaciones definitivas de planes generales (que son, en definitiva, los instrumentos legitimados para la conformación del modelo territorial para el municipio) a lo largo de la última década. Se realiza en el apartado segundo del documento un análisis estadístico, ilustrativo del estado actual del planeamiento urbanístico municipal, detallándose el número de planes generales

\footnotetext{
${ }^{3}$ Véase al respecto, para un pormenorizado detalle, el relato elaborado por el maestro Fernando DE TERÁN en "Planeamiento Urbano en la España Contemporánea. Historia de un proceso imposible" o "Historia del Urbanis mo en España, siglos XIX y XX".

${ }^{4}$ https://www.fomento.gob.es/portal-del-suelo-y-politicas-urbanas atlas-estadistico-de-las-areas-urbanas/atlas-digital, consultado el 24 de febrero de 2019
}

aprobados durante los últimos años utilizando para ello las fuentes del Ministerio de Fomento y de las diferentes Comunidades Autónomas puestas a disposición del usuario a través del Atlas digital de las áreas urbanas ${ }^{4}$. En el tercer apartado se refiere la incidencia que la aparición del proyecto urbano articulado mediante procesos de planificación estratégica tiene sobre el planeamiento urbanístico municipal y, por ende, sobre la conformación del modelo urbano-territorial del propio municipio. En el cuarto apartado se establecen las conclusiones alcanzadas.

\section{Estado actual del planeamiento urbanístico municipal}

El análisis del planeamiento urbanístico municipal se aborda en el presente documento desde la explotación de los datos estadísticos obrantes en la administración nacional y autonómica, a través del recurso en línea Atlas digital de las Áreas Urbanas del MITMA, valorándose principalmente la fecha de aprobación de los planes generales de cada uno de los municipios españoles, y ello no porque se asocie dicha fecha con la idoneidad del modelo planteado por el propio instrumento (esto es, no necesariamente debe concluirse que por haber sido un plan general aprobado mucho tiempo atrás, deba ser considerado como un "mal" plan y viceversa, no por ser reciente debe ser un "buen" plan) pero sí debiéndose concluir sobre la obsolescencia del mismo cuando hayan transcurrido más de ocho años desde dicha aprobación (este es el plazo de programación dispuesto por la legislación ${ }^{5}$ ) o incluso una década (periodo de tiempo más razonable para el desarrollo de este tipo de instrumentos) y lo que es más importante cuando la aprobación de dicho instrumento se ha producido con anterioridad a la legislación vigente (en cada comunidad autónoma) y por tanto no se encuentre adaptado a la misma.

Este último aspecto resulta de especial relevancia, en estos tiempos en los que la legislación debe a su vez adaptarse a los vertiginosos cambios sociales y medioambientales producidos, evidenciándose en este sentido una gran obsolescencia normativa, ya que, de las 17 comunidades autónomas,

${ }^{5}$ Debe señalarse que, si bien el incumplimiento de los plazos de programación no implica la caducidad del planeamiento (ya que los planes tienen vigencia indefinida -STS 223 01- hasta tanto se produzca su revisión o modificación), sí que supone el fracaso del modelo de ordenación que se determina en el propio planeamiento ya que este se formula en congruencia con la programación incluida en el mismo. 
9 aún tienen leyes aprobadas en su mayoría a principios de la primera década del siglo, algunas incluso fueron aprobadas en el siglo XX. Las legislaciones autonómicas urbanísticas que sí han logrado ser aprobadas ya en la presente década incluyen -en su mayoría- disposiciones relativas a aquellos extremos en los que se han evidenciado los principales problemas de la práctica urbanística para los planes generales: tiempos en su tramitación (las nuevas legislaciones incluyen "ventanillas únicas" y coordinación interadministrativa, aprobación autonómica para la ordenación estructural pero municipal para la pormenorizada), adaptación a directivas europeas de sostenibilidad (evaluación ambiental estratégica y vivienda social) y gestión (agente urbanizador y valoración del suelo). Todas estas cuestiones dejan en situación de obsolescencia a aquellos planes que se han formulado y aprobado al margen de las nuevas directrices en estas materias generando además tremendos vacíos jurídicos que se traducen en sorprendentes decisiones judiciales ${ }^{6}$ relativas a la interpretación de las disposiciones de esos instrumentos en el nuevo marco normativo, así como la transitoriedad de las mismas.

Según el Atlas Digital de las Áreas Urbanas del Ministerio de Fomento, de los más de ocho mil municipios que conforman el territorio español, casi 1.500 (1.414, prácticamente uno de cada seis) no tiene ningún tipo de planeamiento municipal aprobado, más de 3.000 (3.029, casi 4 de cada diez municipios) cuenta con Normas Subsidiarias como documento de planeamiento municipal y más de mil (1.211, uno de cada ocho municipios) solo tiene aprobada una Delimitación de Suelo. (ver FIG. 1).

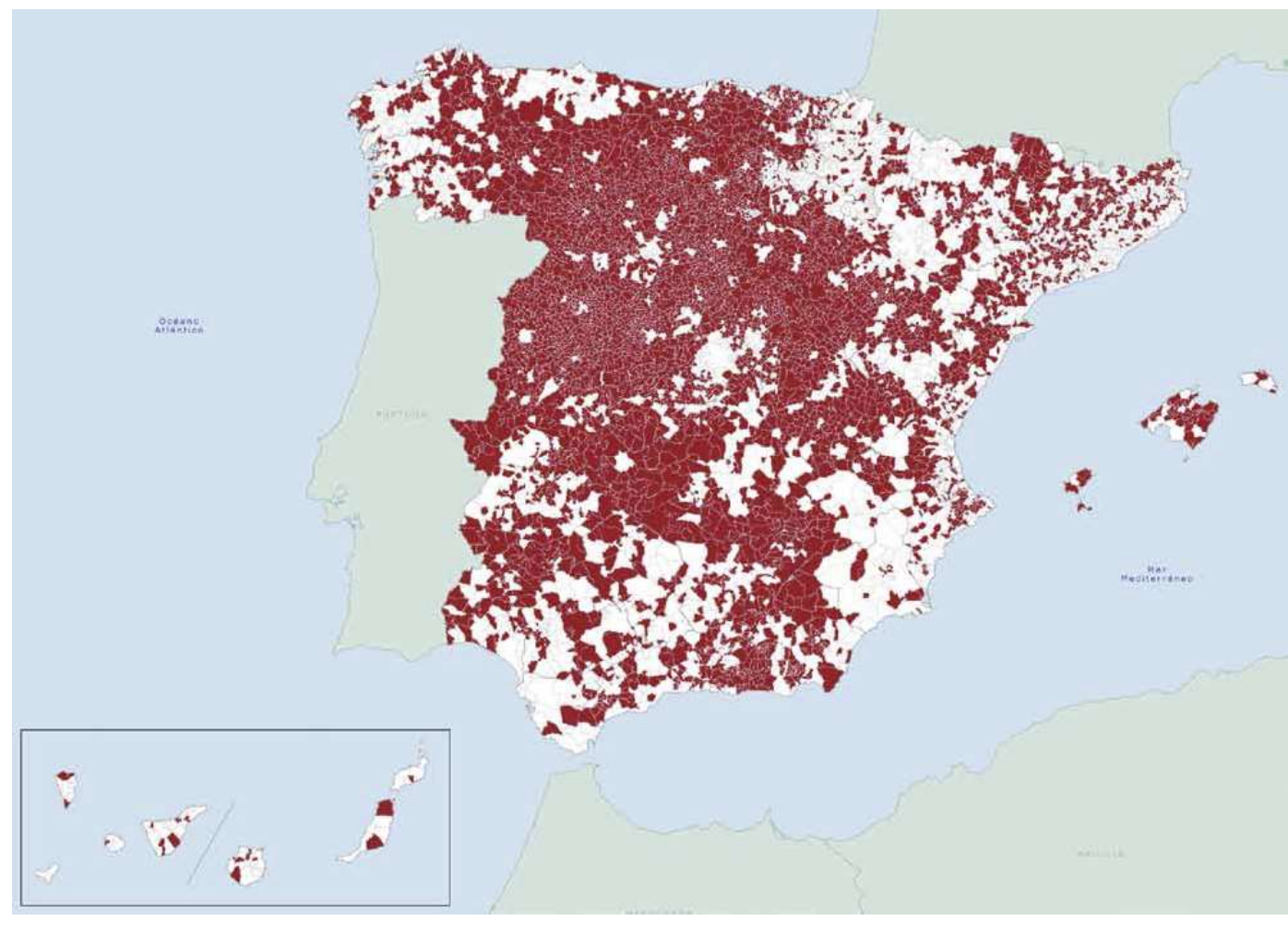

FIG. 1/ Municipios sin plan general aprobado.

Fuente: Atlas digital de las áreas urbanas. Ministerio dE FomENTO.

${ }^{6}$ Véase al respecto, y como ejemplo, la sentencia que supuso la anulación del Plan General de Marbella, fruto entre otros fundamentos jurídicos del "desarrollo invertido" (GUTIÉRREZ: 2016) del proceso legislativo. Este plan, aprobado en 2010 según la sentencia, no se alineaba con la Directiva Europea de 2001 para Evaluación Ambiental Estratégica, que no fue introducida en el ordenamiento jurídico andaluz hasta 2015 , y también desfiguraba el concepto de suelo urbano consolidado, al obrar de forma improcedente el plan al considerar determinados terrenos como suelo urbano no consolidado (OLMEDo: 2009), diferenciación que debe ser interpretada en compatibilidad con la ley estatal, en este caso la legislación estatal de aplicación era el TRLS 08 vigente en el momento de aprobación del plan y no, como sostiene la sentencia la LS 98 . 
Por tanto, casi el $69 \%$ de los municipios del territorio español, no cuenta con un plan general aprobado, ya sea por no contar con ninguna figura de planeamiento o haberse limitado al establecimiento de unas normas subsidiarias de planeamiento o una simple delimitación de suelo urbano, ambos instrumentos de carácter limitado, este último en ningún caso garante de la determinación de un modelo urbano territorial para el municipio en el que se haya aprobado y un instrumento condicionado y también limitado para el caso de las Normas Subsidiarias en relación con el contenido de un plan general. En el 31\% restante de municipios, en los que sí se cuenta con plan general (y en los que se asientan más de 38 millones de habitantes, el $83 \%$ de la población residente en España) solo el $40 \%$ cuenta con su plan general aprobado en la última década, por lo que puede afirmarse, en conclusión, que de la totalidad de municipios españoles solo el $12 \%$ presenta un modelo de ciudad temporalmente actualizado y ajustado a las determinaciones de la legislación correspondiente. Menos de la mitad de municipios de España cuenta con instrumento de planeamiento municipal aprobado en los últimos veinte años (ver FIG. 2).
Si nos referimos a planes generales adaptados a la legislación urbanística vigente en cada comunidad autónoma (las competencias en urbanismo están asignadas a las mismas) más de 6.000 municipios tienen su planeamiento municipal aprobado con anterioridad a la ley urbanística vigente respectiva en su comunidad, lo que supone que tres de cada cuatro municipios en España tienen su modelo de ciudad adoptado en el planeamiento municipal no adaptado a la legislación vigente. Bien es cierto que en varias comunidades la legislación vigente ha sido aprobada recientemente, por lo que no ha transcurrido aún el tiempo suficiente para que la aprobación de un instrumento de este calado se pueda haber producido, sin embargo no deja de ser muy llamativo que en comunidades autónomas con una legislación urbanística con casi dos décadas de antigüedad (Madrid, Andalucía, Castilla León, País Vasco, Cantabria, La Rioja) no se supere el tercio de municipios con plan general adaptado a su propia legislación, esto es, solo uno de cada tres municipios ha adaptado su modelo de ciudad a legislación vigente en estas comunidades autónomas, que, debe ser señalado, representan casi el $45 \%$ de la población española (ver FIG. 3).

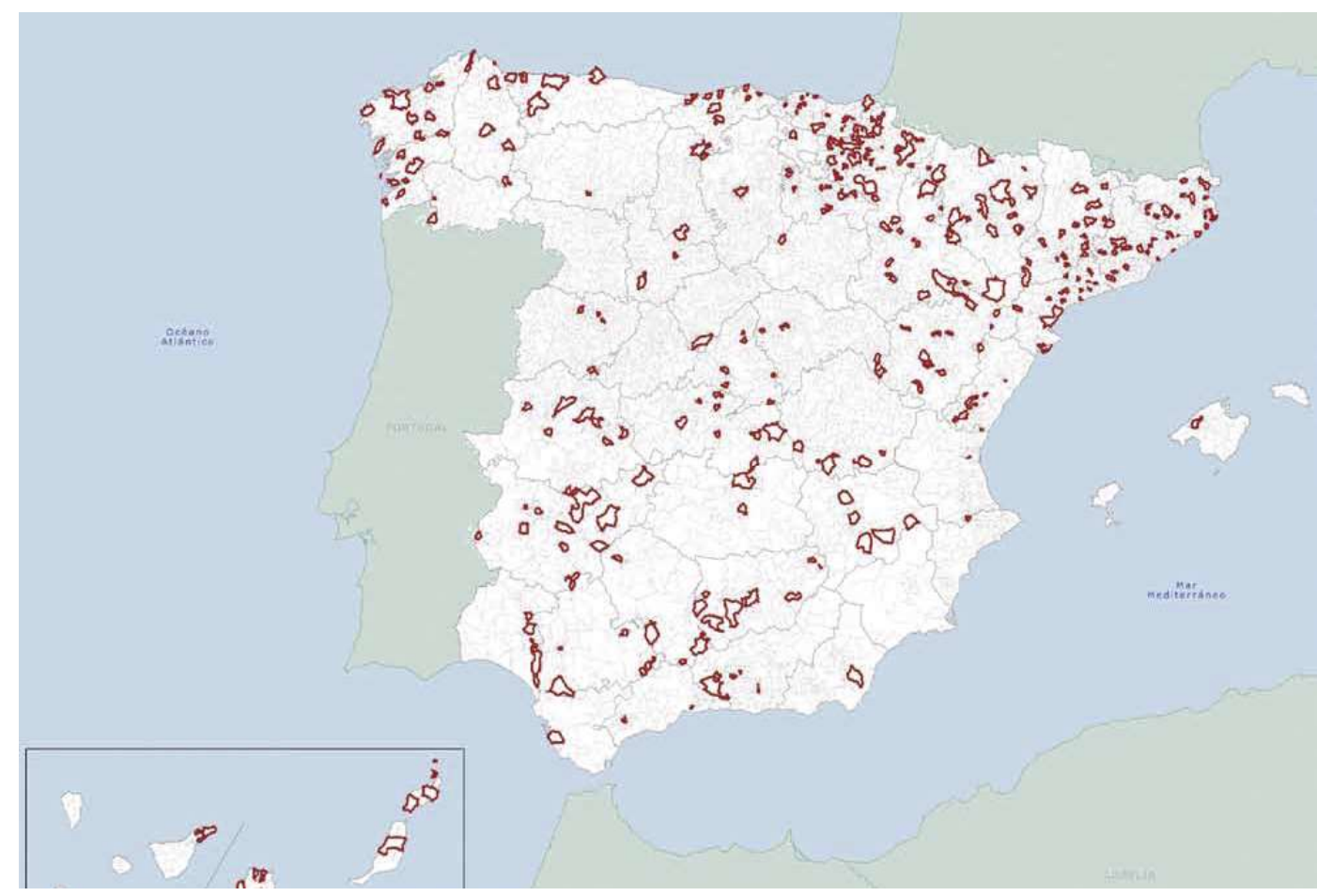

FIG. 2/ Municipios con plan general aprobado en los últimos cinco años.

Fuente: Atlas digital de las áreas urbanas. MINISTERIO DE FOMENTO. 


\begin{tabular}{|c|c|c|c|}
\hline Comunidad Autónoma legislación urbanística & Fecha & $\begin{array}{l}\text { No Adaptado/ } \\
\text { Total }\end{array}$ & $\begin{array}{c}\% \\
\text { No Adaptado }\end{array}$ \\
\hline $\begin{array}{l}\text { ANDALUcíA. Ley } 7 / 2002 \text {, de } 17 \text { de diciembre, de Ordenación Urbanística } \\
\text { de Andalucía }\end{array}$ & 2002 & $578 / 779$ & 74 \\
\hline $\begin{array}{l}\text { CATALUÑA. Decreto Legislativo } 1 / 2010 \text {, de } 3 \text { de agosto, por el que } \\
\text { se aprueba el Texto refundido de la Ley de urbanismo }\end{array}$ & 2010 & $711 / 947$ & 75 \\
\hline $\begin{array}{l}\text { COMUNIDAD DE MADRID. Ley 9/2001, de } 17 \text { de julio, del Suelo } \\
\text { de la Comunidad de Madrid }\end{array}$ & 2001 & $149 / 179$ & 83 \\
\hline $\begin{array}{l}\text { COMUNIDAD VALENCIANA. Ley } 5 / 2014 \text {, de } 25 \text { de julio, } \\
\text { de la Generalitat, de Ordenación del Territorio, Urbanismo y Paisaje, } \\
\text { de la Comunitat Valenciana }\end{array}$ & 2014 & $519 / 542$ & 96 \\
\hline GALICIA. LEY 2/2016, de 10 de febrero, del Suelo de Galicia & 2016 & $294 / 313$ & 94 \\
\hline $\begin{array}{l}\text { CASTILLA Y LEON. Ley 5/1999, de } 8 \text { de abril, de Urbanismo } \\
\text { de Castilla y León }\end{array}$ & 1999 & $2.184 / 2.248$ & 97 \\
\hline PAIS VASCO. Ley $2 / 2006$, de 30 de junio, de Suelo y Urbanismo & 2006 & $188 / 251$ & 75 \\
\hline $\begin{array}{l}\text { CANARIAS. Ley } 4 / 2017 \text {, de } 13 \text { de julio, del Suelo y de los Espacios } \\
\text { Naturales Protegidos de Canarias }\end{array}$ & 2017 & $85 / 88$ & 97 \\
\hline $\begin{array}{l}\text { CASTILLA LA MANCHA. Decreto Legislativo } 1 / 2010 \text {, de 18/05/2010, } \\
\text { por el que se aprueba el texto refundido de la Ley de Ordenación } \\
\text { del Territorio y de la Actividad Urbanística }\end{array}$ & 2010 & $873 / 919$ & 95 \\
\hline $\begin{array}{l}\text { REGIÓN DE MURCIA. Ley 13/2015, de } 30 \text { de marzo, de Ordenación } \\
\text { Territorial y Urbanística de la Región de Murcia }\end{array}$ & 2015 & $45 / 45$ & 100 \\
\hline $\begin{array}{l}\text { ARAGÓN. Decreto-Legislativo } 1 / 2014 \text {, de } 8 \text { de julio, del Gobierno de Aragón, } \\
\text { por el que se aprueba el texto refundido de la Ley de Urbanismo de Aragón }\end{array}$ & 2014 & $682 / 731$ & 93 \\
\hline $\begin{array}{l}\text { ISLAS BALEARES. Ley 12/2017, de } 29 \text { de diciembre, de urbanismo } \\
\text { de las Illes Balears }\end{array}$ & 2017 & $67 / 67$ & 100 \\
\hline $\begin{array}{l}\text { EXTREMADURA. Ley } 11 / 2018 \text {, de } 21 \text { de diciembre, de ordenación territorial } \\
\text { y urbanística sostenible de Extremadura }\end{array}$ & 2018 & $388 / 388$ & 100 \\
\hline $\begin{array}{l}\text { ASTURIAS. Decreto Legislativo } 1 / 2004 \text {, de } 22 \text { de abril, por el que } \\
\text { se aprueba el Texto Refundido de las disposiciones legales vigentes } \\
\text { en materia de ordenación del territorio y urbanismo }\end{array}$ & 2004 & $36 / 79$ & 46 \\
\hline $\begin{array}{l}\text { CANTABRIA. Ley de Cantabria 2/2001, de } 25 \text { de junio, de Ordenación } \\
\text { Territorial y Régimen Urbanístico del Suelo de Cantabria }\end{array}$ & 2001 & $79 / 103$ & 77 \\
\hline $\begin{array}{l}\text { NAVARRA. Decreto Foral Legislativo } 1 / 2017 \text {, de } 26 \text { de julio, por el que } \\
\text { se aprueba el Texto Refundido de la Ley Foral de Ordenación del Territorio } \\
\text { y Urbanismo }\end{array}$ & 2017 & $259 / 272$ & 95 \\
\hline $\begin{array}{l}\text { LA RIOJA. Ley } 5 / 2006 \text {, de } 2 \text { de mayo, de Ordenación del Territorio } \\
\text { y Urbanismo de La Rioja }\end{array}$ & 2006 & $113 / 174$ & 65 \\
\hline
\end{tabular}

Si el análisis se centra en el sistema de ciudades, de las 62 que cuentan con más de 100.000 habitantes, solo 10 , esto es una de cada seis ciudades, tiene plan general aprobado en los últimos diez años. De las que superan 50.000 solo 24 , un $16,6 \%$, tienen su planeamiento aprobado en la presente década y solo en 29 de ellas, o lo que es lo mismo, en una de cada cinco ciudades con más de 50.000 habitantes se ha aprobado un plan general en la última década. Tan solo
1.225 municipios tienen su planeamiento general municipal aprobado en los últimos diez años y con posterioridad a la aprobación de la legislación vigente de la comunidad autónoma en la que se localizan. Solo el $15 \%$ de los municipios de España cuenta por tanto con un modelo de ordenación urbano territorial adaptado a la legislación vigente y adoptado bajo criterios normativos más acordes con los nuevos principios de un urbanismo más sostenible (ver FIG. 4). 


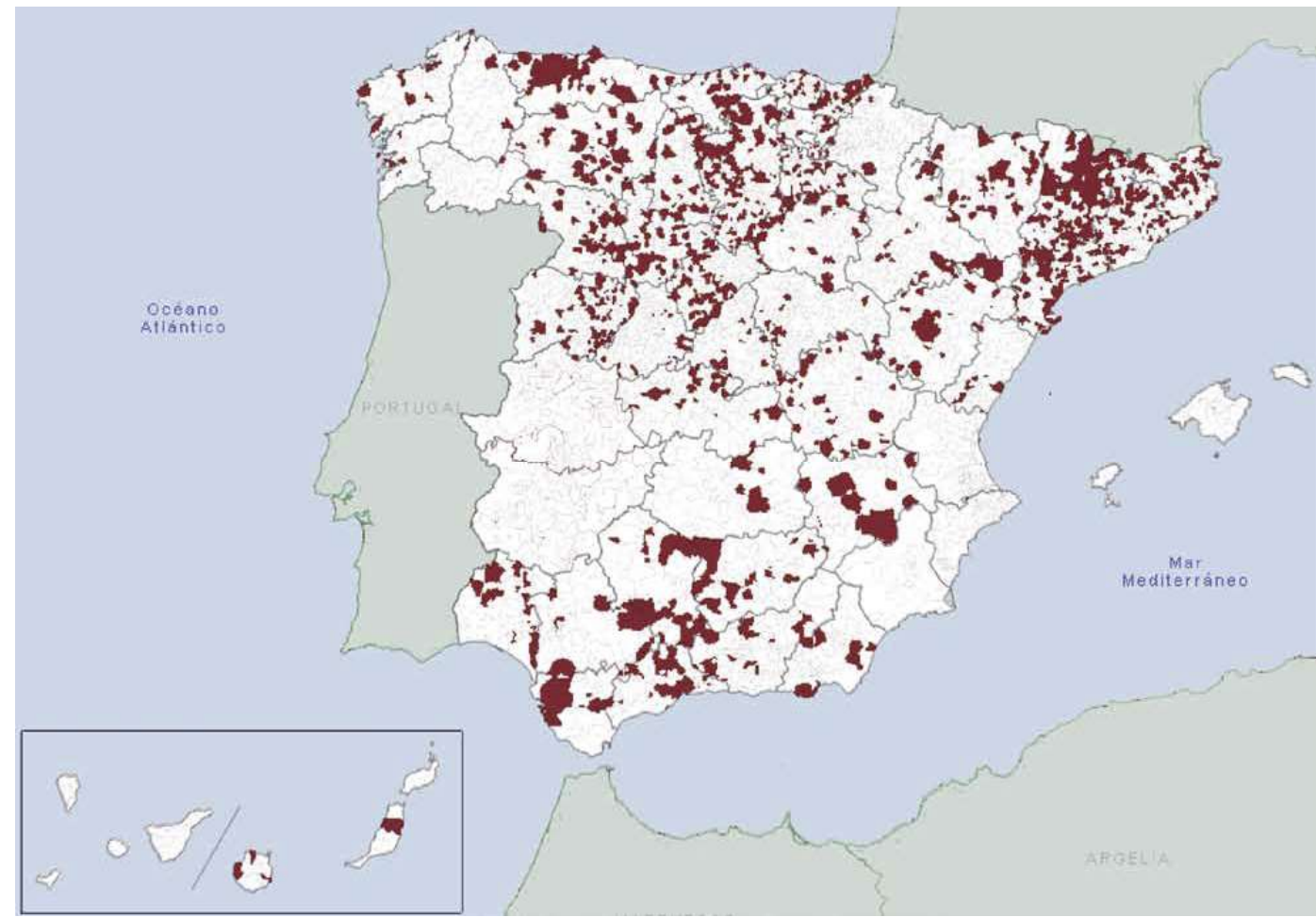

FIG. 4/ Municipios con planes generales adaptados a la legislación vigente en cada comunidad autónoma y aprobados en la última década.

Fuente: Atlas estadístico de las áreas urbanas. Elaboración propia

Si se atiende a la evolución seguida durante lo que va de siglo en relación al número de planes generales aprobados en España, pueden sacarse varias conclusiones: por un lado, el mayor número de planes generales aprobados se alcanza en el año 2003, año caracterizado por la expansión económica lograda, pudiendo establecerse una relación causal entre la situación económica y la intensidad de la redacción de este tipo de documentos. Sin embargo, se constata un repunte en el año 2010 del número de planes generales aprobados, año caracterizado por la fuerte incidencia de los efectos de la crisis, evidencia de la importancia de otros factores en la causalidad de dicho repunte; de otro lado, se produce una fuerte caída en número de planes generales aprobados durante los últimos años, descendiendo desde los 170 aprobados en 2015 a 64 en 2016, 26 en 2017 y 18 en 2018, años en los que se han ido mejorando uno tras otro los indicadores macroeconómicos en territorio español, mejora que no ha sido trasladada a un repunte en el número de planes generales aprobados.

Estos datos vienen a confirmar ya no solo la situación de crisis en la que se encuentra el planeamiento urbanístico municipal sino su dramática evolución. Algo no está funcionando en este país -de más de 8.000 municipios- cuando en un año solo se aprueba un documento del calado de un plan general en 18 de ellos, sobre todo si se tiene en cuenta que cuatro de cada cinco de estos ocho mil municipios no tiene su plan general adaptado a la legislación vigente y que uno de cada cinco ni siquiera cuenta con plan general. (ver FIG. 5)

Los datos referidos a 2019 merecen una reflexión más incisiva, sobre todo si se pretenden extraer de su análisis conclusiones constructivas para revertir la situación crítica en la que se encuentra el planeamiento urbanístico en gran parte del territorio español. Se han aprobado durante ese año 40 planes generales a nivel nacional, número que invierte la tendencia regresiva del último lustro, pero que supone -todavía- la tercera peor cifra en los últimos 20 años, por lo que, si bien dicha cantidad representa un crecimiento con respecto a los dos anteriores años, no permite extrapolar un posible cambio de ciclo. Si los datos son desglosados por comunidades autónoma, en las que se han aprobado planes generales han sido: Aragón (1), 


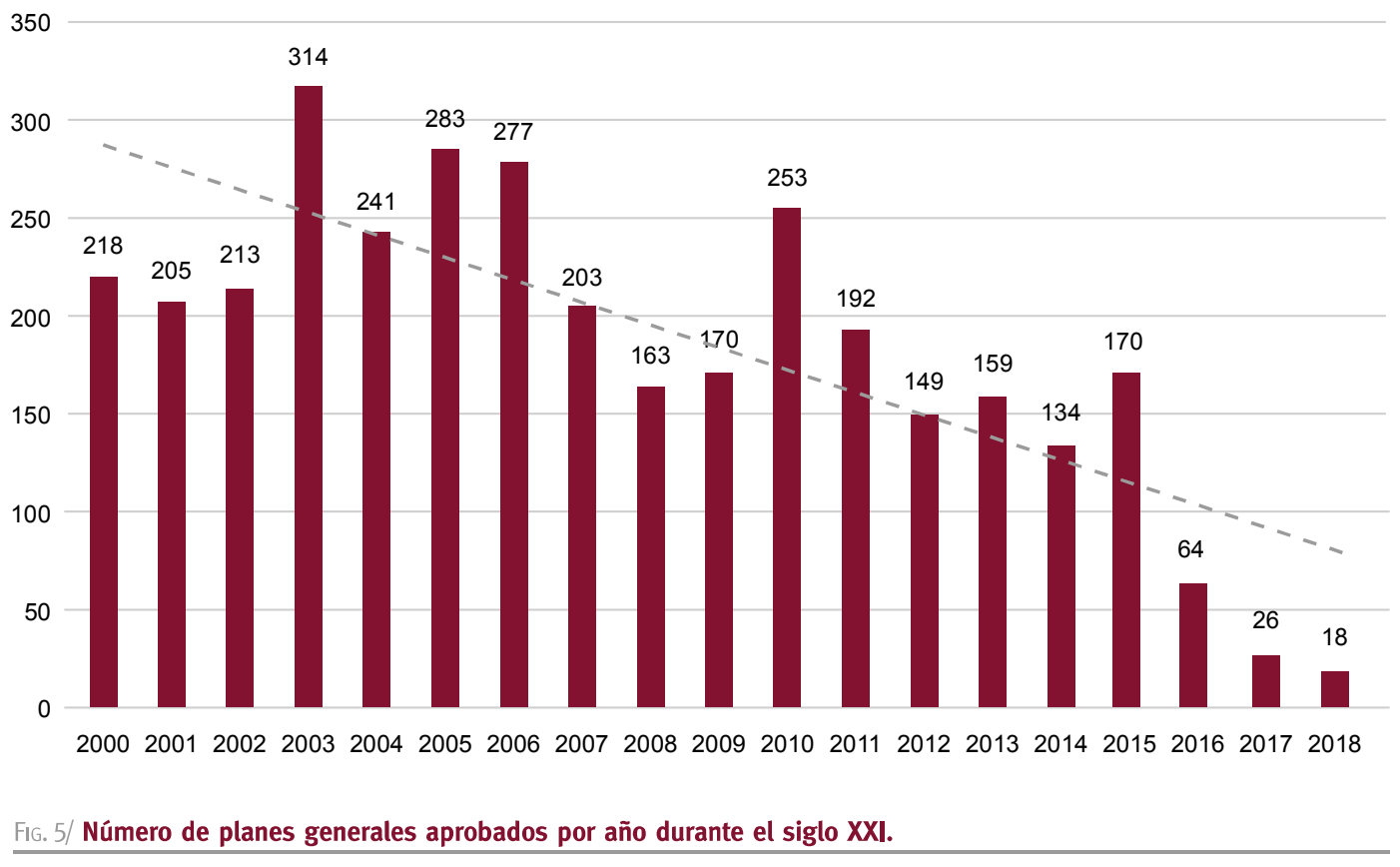

Fuente: Atlas estadístico de las áreas urbanas. Elaboración propia.

Canarias (1), Asturias (2), Andalucía (2), Galicia (3), Navarra (8), Valencia (9) y Cataluña (14), no habiéndose aprobado ningún plan general en las otras nueve restantes. Puede comprobarse de la lectura de estos datos que en aquellas comunidades en las que se ha actualizado su legislación en la última década, casos de Cataluña, Valencia, y Navarra, prolifera en mayor medida la aprobación de nuevos planes generales, ocurriendo justo lo contrario en aquellas comunidades con legislaciones vigentes aprobadas en la primera década de siglo, deduciéndose de todo ello la necesidad de procederse en estas regiones a la actualización de su legislación regional, como incentivo para la revisión y actualización de los modelos urbanos de sus municipios (los casos más dramáticos son los de Castilla-León, Madrid, Cantabria y Andalucía con leyes vigentes aprobadas en 1999, 2001 y 2002 respectivamente).

\section{Sin plan no hay planeamiento, sin planeamiento no hay modelo. Sin modelo no hay ciudad}

La constatación de problemas ambientales derivados del fenómeno del cambio climático, así como los cambios sociales derivados de la adopción de nuevos modelos de consumo y gobernanza, así como la adaptación del territorio al nuevo ciclo demográfico hacen necesaria la implementación de políticas urbanas que tengan en consideración sus consecuencias, de tal manera que la necesidad de un planeamiento urbanístico más sostenible y resiliente es hoy en día más necesaria que nunca.

“... el ecourbanismo aspira a conseguir lo que siempre se debió hacer, es decir, "articular las múltiples y complejas variables que intervienen en una aproximación sistemática al diseño urbano alejándose de planteamientos exclusivamente formalistas o sectoriales y recuperando la visión integrada y unificada del urbanismo"; a mayor abundamiento, el planeamiento urbano sostenible sería el único medio viable para acomodar las actividades urbanas en un entorno cada vez más deteriorado y amenazado" (RuANo,1999: 10-11).

La comprobación de que muchos municipios no tienen plan general aprobado, pero sobre todo, de que muchos municipios tienen un plan general aprobado hace más de una década ( $y$ más de dos décadas también en muchos casos) viene a escenificar un panorama en el urbanismo español caracterizado por la presencia de un planeamiento urbanístico sin plan general (adaptado a este tipo de políticas), dada la ausencia o invalidez de esta herramienta, que muestra grandes signos de obsolescencia con el paso de sus propios plazos de programación, transcurridas una -y máxime dos- décadas de 
desarrollo y ante períodos de gran convulsión y cambios como los acontecidos en los últimos años.

De todo ello se deriva la profunda crisis de este documento en los últimos años y el cuestionamiento del mismo como herramienta metodológica, algo que no siendo ni mucho menos nuevo ${ }^{7}$, tiene cada vez mayor relevancia para gestores y ciudadanía a la hora de poner en marcha la conformación de un nuevo modelo de ordenación para el territorio adaptado a nuevas necesidades y demandas, desechándose de esta manera la iniciativa de un proceso de revisión de planeamiento, y apostándose por otro tipo de procesos para el desarrollo de dicho territorio.

La generación de planes generales ha tenido una tendencia decreciente en las últimas dos décadas, siendo especialmente notorio dicho descenso en los cinco años. Las causas de esta situación conforman un complejo sistema cuyos componentes se retroalimentan, provocando la cronificación y exacerbación de la "crisis del planeamiento" (FONT, 2000:78): entre las más actuales destacan desde la inseguridad jurídica que está provocando la nulidad "radioactiva" de los planes urbanísticos por defectos en el procedimiento de aprobación (RENAU, 2016), hasta la irrupción de cuestiones transversales como las perspectivas de género, familia, adolescencia, cambio climático, salud y el análisis del impacto que tiene el desarrollo del plan general sobre las mismas, lo que a su vez tiene una incidencia directa en la ya de por sí lenta maquinaria administrativa encargada de resolver la viabilidad de estos documentos, eternizando y convirtiendo en quimérica la aprobación definitiva de los propios planes generales.

Se observa, sin embargo, al mismo tiempo, una clara y decidida apuesta desde los municipios (especialmente en capitales y grandes aglomeraciones urbanas) por la planificación estratégica. Una planificación ad hoc, más acotada e inclusiva, con técnicas propias de métodos

\footnotetext{
7 Se puede situar el declive del paradigma del urbanismo funcionalista (MoncLús, Javier, 2017: 102) predominante en la disciplina urbanística ya en la década de los setenta, en medio de una crisis no solo económica que evidenció la ambivalencia del zonning como método científico racionalista ante las diferentes culturas territoriales presentes en cada país. El surgimiento en los ochenta de proyectos urbanos estratégicos abanderados por la deriva morfológica y la dimensión proyectual de la forma urbana imperante en ese momento supusieron una crítica feroz al plan, si bien la deriva desregulatoria que adoptó la primacía del proyecto del fragmento urbano que, a la postre, buscaba eliminar cualquier impedimento subyacente al establecimiento de un proyecto global de ciudad obligó a muchos de esos críticos a retractarse públicamente (GóRgOLAS. 2016: 45).
}

corporativos asociados al interés del empresariado usada para la conformación de los modelos (no "solo" urbanos, también turísticos, comerciales...) pretendidos para la ciudad que, ayudada por la influencia de las políticas europeas en torno a este tipo de planificación y su vinculación con la asignación de fondos FEDER ${ }^{8}$, viene a consolidarse como alternativa al plan general como herramienta dinamizadora de proyectos urbanos.

Con la tramitación de este tipo de proyectos se ha ido sorteando la necesidad de la revisión del modelo urbano territorial existente (y por tanto la causalidad de la redacción de un nuevo plan) que este tipo de actuaciones supone. Abordar la problemática urbana de las ciudades por medio de la resolución de conflictos puntuales y la ordenación fragmentada del espacio mediante un diseño formal (y programático) que se vehiculiza al margen del planeamiento general, provoca que se pierda la óptica global e integradora que aglutina los diferentes fragmentos (proyectos). Pese a todo ello, siguen apareciendo multitud de proyectos urbanos asociados o no a eventos singulares $y / 0$ vinculados a estrategias de desarrollo urbano sostenible que persiguen, en muchos casos, generar inversiones en lugar de generar ciudad. Sin ir más lejos, de las 454 estrategias DUSI presentadas en la $1^{\mathrm{a}}$ y $2^{\mathrm{a}}$ convocatoria ${ }^{9}$, solo 123 han sido seleccionadas pese a la experiencia acumulada en este tipo de intervenciones. ${ }^{10}$

La consolidación de este modelo de gestión surgida -normalmente- a golpe de eventos singulares e intereses de la promoción inmobiliaria, que sustituye o modifica al planeamiento general en el que debieran enmarcarse, hace que se distorsione el modelo que subyace a dicho planeamiento general, perdiéndose por ello la "idea" de ciudad que contiene y provocando el olvido de toda la comunidad sobre el territorio perdiendo a su vez el control sobre el mismo.

\footnotetext{
8 (ROMERo, 2018: 11).

${ }^{9}$ El artículo 7 del Reglamento FEDER (Reglamento (UE) $n$. $1301 / 2013$ ), recoge que a lo largo del periodo 2014-2020 al menos un $5 \%$ de los recursos de este fondo deberá ser destinado a financiar medidas integradas para el desarrollo urbano sostenible, en las que las ciudades, los organismos subregionales o locales responsables de la aplicación de estrategias urbanas sostenibles serán los encargados de las tareas relacionadas, por lo menos, con la selección de las operaciones

http://www.rediniciativasurbanas.es/convocatoria-de-ayudas/ estrategias-dus

${ }^{10}$ Véase al respecto la obra Arquitectura Milagrosa, de Llatzer MOIX, muy ilustrativa en este sentido.
} 
Una primera consecuencia de todo ello es la continuada modificación del planeamiento general, en lugar de su revisión. La constante innovación del planeamiento general vía modificación puntual contribuye a legitimar esta manera de proceder, al insertarse estos proyectos en el marco de la planificación estratégica (también desde la planificación territorial) de tal manera que la misma sirva de aval y justificación a los ya preconcebidos proyectos urbanos pretendidos por las distintas ciudades.

Llama poderosamente la atención que, si bien en ninguna de las principales capitales españolas se ha podido redactar un plan general desde el siglo pasado, sí que en todas ellas se ha aprobado multitud de planes estratégicos y que si bien se pueden contar más de $120^{11}$ municipios que tienen Plan Estratégico aprobado, solo en 14 de ellos se ha aprobado un plan general en la última década.

En uno de los ejemplos más relevantes de auditoría a la planificación estratégica realizados en España, incluido en el número 13 de la revista Elementos de debate territorial de la Diputación de Barcelona, se puede leer lo siguiente:

"[...] La utilización por buena parte de los planes estratégicos del "método Barcelona" sirvió para profundizar los temas de participación y colaboración ciudadana, pero ayudó poco a definir una estrategia a los municipios y en concreto a los ayuntamientos que no la poseían. A juicio de la publicación de no pocos planes estratégicos (pero no de todos y ni siquiera la mayoría de ellos), su objetivo central o, incluso, su modelo de ciudad consiste solo en unos criterios generales de calidad de vida urbana... De los tres objetivos diferenciados que debe plantearse un Plan Estratégico Territorial (la definición de una estrategia de ciudad, la cooperación pública y privada entre los principales actores urbanos para llevar a cabo dicha estrategia y la participación y colaboración ciudadana en el proyecto de futuro), los planes estratégicos han priorizado la colaboración y participación ciudadana. [...]"

Ese documento acredita la idoneidad de la planificación estratégica como vehículo transmisor entre los diferentes agentes y la ciudadanía, un tipo de documento más político que jurídico y/o técnico, y consolida la función pretendida en realidad para este tipo de documentos: su capacidad para generar foros de publicitación de programas políticos que por la generalidad e inconcreción de sus objetivos han demostrado ser un gran cajón "de-sastre" donde cualquier proyecto sea o no estratégico, pueda tener cabida. $\mathrm{Si}$, como concluye la publicación de la Diputación de Barcelona referida, los planes estratégicos solo sirven en gran medida o solo se utilizan principalmente para dar conocimiento a la ciudadanía de los objetivos o la idea que se tiene de un modelo de ciudad o incluso de un solo proyecto, bien se podría ahorrar toda esta "escenografía" y procurar que el documento que real y legalmente debe ejercer esa función sea mucho más participativo y publicitado.

Si bien de todo ello no puede dirimirse la cuestión de la validez del planeamiento estratégico como herramienta de gestión municipal, sí puede cuestionarse su condición de agente impulsor del planeamiento, legitimándose como una plataforma de comunicación y, en cualquier caso, de dinamización de proyectos, pero no conformadora de un modelo de ciudad.

\section{Conclusiones}

De que el planeamiento urbanístico general sufre desde hace más de una década de crisis crónica no puede haber sombra de duda. Los datos lo ponen de-contundente-manifiesto (solo uno de cada cinco municipios ha redactado $z$ su plan en los últimos diez años, teniendo en cuenta además que de los más de 8.000 municipios españoles unos 1.500 aún no cuentan con plan general). Una crisis sistémica del propio sistema, que inviabiliza ya sea por lentitud administrativa, costes, politización de la herramienta, etc. la conformación de modelos de ordenación urbano-territorial válidos. Los últimos datos estadísticos del atlas digital de las áreas urbanas del Ministerio de Fomento no hacen más que confirmar una de las hipótesis del presente artículo: el rechazo a la consideración del planeamiento general y/o su incapacidad como instrumento operativo para desarrollar el modelo (sostenible y funcional) de ordenación del territorio municipal. Sirva un dato demoledor: solo se aprobaron 18 planes generales en el año 2018 (lo que supone apenas el $0,2 \%$ de los municipios españoles)

Si bien las señales de advertencia sobre la inoperatividad del planeamiento urbanístico en España

${ }_{11}$ Puede accederse a un listado de 122 planes estratégicos en el documento La planificación estratégica territorial y urbana en España hoy. Realizado por Guillermo Benito en marzo de 2016. 
no han cesado a lo largo de la última década ${ }^{12}$, la tendencia observada en los últimos años no solo viene a confirmar el empeoramiento de este problema, sino que le confiere tintes de drama. En España, tres de cada cuatro municipios cuentan con un plan general obsoleto, al haberse superado los plazos temporales de su programación y/o haberse aprobado dicho instrumento con anterioridad a la legislación urbanística vigente en su respectiva comunidad autónoma. Esto significa que la mayoría de los municipios sigue contando a día de hoy con un modelo urbanístico basado en unos criterios y objetivos ya superados y normalmente contrarios a los nuevos principios del urbanismo -más sostenibles- que necesitan los territorios, modelos urbanos generados en base casi exclusiva al crecimiento, negacionistas con los principios de regeneración y rehabilitación urbanas (principios introducidos de manera taxativa a partir de la Ley del Suelo de 2008, posteriormente refundida en el TRLSRU 2015).

La aprobación de modificaciones puntuales o parciales del planeamiento vigente (articuladas a través de la generación de proyectos urbanos estratégicos y/o planes estratégicos), ha sido y está siendo la fórmula mágica elegida por muchas administraciones municipales, una técnica urbanística no pretendida por la legislación pero difícil de impedir, tónica del urbanismo español de los últimos años, un urbanismo que puede ser adjetivado como "miope", caracterizado por una gran visión de cerca, muy válido para el establecimiento de modelos de ordenación operativos en el corto plazo, pero prácticamente ciego en las distancias más largas, esto es, en el análisis que las consecuencias de dichos modelos tienen sobre la ciudad en la que se desarrollan, una praxis que puede ser muy peligrosa para el soporte territorial en el que se implante.

De todo esto no debe deducirse que no puedan implementarse modificaciones de planes y/o

\footnotetext{
12 Destaca de entre las mismas el post publicado en el Blog de FARIÑA en 2008 titulado Planeamiento Obsoleto https://elblogdefarina.blogspot.com/2008/05/planeamientoobsoleto.html, consultada el 24 de febrero de 2019.

13 "Literalmente pide a las autoridades españolas que desarrollen una cultura de la transparencia dirigida a informar a los ciudadanos de la gestión del suelo y a impulsar mecanismo de información y participación ciudadana efectivos... (CHINCHILLA, 2016).

${ }^{14}$ El Plan General de Ordenación Urbanística de Sevilla de 2006, premio especial AETU en la 6TH European Urban and Regional Planning Awards 2008, del European Concil of Spatial Planners, contó -desde el inicio de su configuración- con numerosos mecanismos para la información y participación
}

proyectos estratégicos, lo que si debe convenirse es que no sean estas y/o estos el motor exclusivo de las políticas urbanas de desarrollo de las ciudades ya que, si bien pueden ser herramientas que difundan y pongan determinadas actuaciones en marcha, no tienen, por su propia naturaleza, la capacidad para intervenir de forma global en el modelo urbano territorial, que genera en definitiva la propia ciudad. Tampoco puede, $\mathrm{ni}$ debe entenderse un plan general sin la inclusión en el mismo de una serie de proyectos urbanos estratégicos que conformen y desarrollen sus propios objetivos, de la misma manera que no puede entenderse que un proyecto urbano considerado como "estratégico" no tenga en cuenta el marco normativo y reglamentario donde se debe desarrollar la propia estrategia que supone su conformación. En este sentido, y con el marco jurídico actual, de lo que se trataría es de integrar las capacidades de la planificación estratégica en el planeamiento urbanístico general, y no seguir entendiendo estas dos herramientas como organismos independientes en la gestión municipal.

Pese al Informe AUKEN en el que el Parlamento Europeo cuestiona la práctica llevada a cabo por los poderes públicos españoles en relación a la participación de los ciudadanos en los procesos urbanísticos ${ }^{13}$, existen ejemplos de planes generales participativos, algunos con premios concedidos -entre otras cosas- por ello ${ }^{14}$ por lo que nada debe hacer pensar en esto como una quimera imposible, solo basta con la buena voluntad de los gestores.

El impulso para la nueva redacción o revisión del plan general sigue siendo potestad municipal, reiterándose desde este ámbito su incapacidad (económica y administrativa) para abordar esa tarea, de lo que se deduce que no solo se puede y se debe desde la administración autonómica establecer mecanismos para aligerar la tramitación sino impulsar e incentivar la propia redacción

púbica, añadiendo a los hitos procedimentales legales para la tramitación de este tipo de planes distintas fases encaminadas a la máxima difusión y participación ciudadana en el documento. Se crearon en este sentido fases como las de "Plan a la Vista" (que supuso la introducción de métodos prospectivos en la redacción de este tipo de documentos, método Delphy por ejemplo), Metaplan (que propició la configuración de 10 workshops temáticos), Prediagnóstico, Diagnóstico, Mesas de Participación y Documento de Conclusiones del Proceso de Participación, que supusieron todos ellos hitos participativos previos a las fases establecidas en la legislación andaluza (Avance, Aprobación Inicial y Aprobación Provisional) generándose de esta manera un planeamiento plenamente compartido y consensuado. 
de este tipo de documentos ${ }^{15}$, circunstancia que debe ser colocada en primer orden de prioridad para las autonomías dada la urgencia con que miles de municipios necesitan establecer mode los acordes con los tiempos que corren. Hoy, más que nunca, se necesita de una concertación interadministrativa eficaz y eficiente, que posibilite las relaciones entre las diferentes potestades jurídicas e implemente la integración de las diferentes políticas sectoriales.

\section{Bibliografía}

Agulles, J. (2017): La destrucción de la ciudad. El mundo urbano en la culminación de los tiempos modernos. Ed. Catarata.

CAPEL, H. (2005): El modelo Barcelona: un examen crítico ( $2^{\mathrm{a}}$ ed. 2009). Ediciones del Serbal, Barcelona.

Cruz Gallach, H. (2008): "El auge de los planes estratégicos y los proyectos urbanos: Hacia un planeamiento urbanístico consensuado. Diez años de cambios en el Mundo, en la Geografía y en las Ciencias Sociales, 1999-2008". Actas del X Coloquio Internacional de Geocrítica, Universidad de Barcelona, 26-30 de mayo de 2008. http://www.ub.es/geocrit/-xcol/308.htm

Delgado Jiménez, A. (2014): Una revisión crítica del planeamiento urbano en la evolución y crisis de la Región Metropolitana de Madrid. Madrid cuestión central. Autonomía y región metropolitana. Ediciones UAM. ISBN: 978-84-8344-433-7. 113-120 pp.

Diez Medina, C. \& Monclús, J. (eds.) (2018): Visiones urbanas. De la cultura del plan al urbanismo paisajístico. ABADA Editores

D.G. de Arquitectura, Vivienda y Suelo. Centro de Publicaciones, Ministerio de Fomento. Ministerio de Fomento. (2010): Libro Blanco de la Sostenibilidad en el Planeamiento Urbanístico Español. https://www.fomento.gob.es/arquitectura-vivienday-suelo/urbanismo-y-politica-de-suelo/urbanismoy-sostenibilidad-urbana/libro-blanco-de-la-sostenibilidad-en-el-planeamiento-urbanistico-espanol

FARIÑA, J. (2008): "Planeamiento obsoleto." El Blog de Fariña.

https://elblogdefarina.blogspot.com/2008/05/ planeamiento-obsoleto.html

Fernández-Ges, A. (2018): Análisis de los proyectos urbanos estratégicos en el contexto europeo,19972017. El caso de Zaragoza, en Ciudad y formas urbanas: perspectivas transversales. Volumen 5. Formas urbanas, planeamiento, proyecto urbano. Universidad de Zaragoza. https://doi.org/10.26754/uz.9788417358846
FoLCH, R. (2017): El Mundo Urbano. http://fundrogertorne.org/salud-infancia-medioambiente/2017/02/07/el-mundo-urbano/

Font, A. (2000): La experiencia reciente de Cataluña. Planeamiento urbanístico para el siglo XXI. En Urban 5 Revista del Departamento de Urbanística y Ordenación del Territorio, Escuela Técnica Superior de Arquitectura, Universidad Politécnica de Madrid, págs. 60-82.

GonzÁlez Fustegueras, M. A. (2009): "El Plan General de Ordenación Urbanística. Contenido Técnico. En Manual práctico de derecho urbanístico de Andalucía", Diputación de Granada, 201.

GóRgolAs, P. (2016): La planificación de la ciudad en el cambio de milenio (1997-2017). Propuestas para reconducir la herencia recibida: los casos de casares (Málaga) y Chiclana de la Frontera (Cádiz). Tesis Doctoral. https://idus.us.es/xmlui/handle/11441/52364

GREENPEACE (2007): "Destrucción a toda costa." Informe anual 2007.

Gutiérrez Colomina, V. (2016): "Los efectos de la nulidad de los planes urbanísticos en Andalucía y su repercusión en las edificaciones ilegales". Revista Andaluza de Administración Pública. ISSN: 1130-376X, núm. 96, septiembre-diciembre (2016), págs. $47-84$

Jurado Almonte, J. M. (2010): "El «vilipendiado» urbanismo: una visión desde la experiencia en la gestión pública" en Cuadernos geográficos de la Universidad de Granada. Sección de Geografía, Facultad de Letras, Universidad de Granada. N. ${ }^{\circ} 47$.

LÓPEZ DE LUCIO, R. (1993): "El ensimismamiento en el "Urbanismo Urbano" como respuesta a las limitaciones del planeamiento territorial". Ciudades, (01), 61. https://doi.org/10.24197/ciudades.01.1993.61-66.

Ministerio de Fomento (2017): "Atlas estadístico de las áreas urbanas".

https://www.fomento.gob.es/portal-del-suelo-y-politicas-urbanas/atlas-estadistico-de-las-areas-urbanas

Moıx, L. (2010.): Arquitectura milagrosa: hazañas de los arquitectos estrella en la España del Guggenheim. Editorial Anagrama

Molina Costa, P., \& Rey MAZón, P. (2017): El urbanismo mágico: megaproyectos en la era del despilfarro. Ciudades, (14), 235.

Olmedo Pérez, S. (2009): "El régimen del suelo urbano y sus categorías de consolidado y no conso-lidado". En Manual práctico de derecho urbanístico de Andalucía, Diputación de Granada, 201.

Pascual Esteve, J. M. (Coord.) (2001): "Estratègies de Qualitat Urbana. De la planificación a la gestión estratégica de las ciudades". Elements de debat territorial. Núm. 13 - gener del 2001. Diputació de Barcelona. Xarxa de Municipies.

PORTAS, N. (2003): "El surgimiento del proyecto urbano". Perspectivas urbanas $=$ Urban perspectives, ISSN: 1695-534X, №. 3.
15 La Orden 94/2018, de 11 de junio, de la Consejería de Fomento, por la que se establecen las bases reguladoras de la concesión de subvenciones a municipios de Castilla-La Mancha para la financiación de actuaciones en materia de redacción de diversos instrumentos de planeamiento urbanístico, constituye uno de los ejemplos más recientes. 
Renau Faubell, F. (2016): "La nulidad "radioactiva" de los planes urbanísticos por defectos en el procedimiento de aprobación". Noticias Jurídicas, 10 de marzo de 2016.

Romero Aloy, M. J. \& VIDAL CLIMENT, V. (2018): Planificación estratégica territorial y alteraciones del plan general, En Ciudad y territorio: Estudios territoriales, № 195, págs. 7-20.

RuANo, M. (1999): Ecourbanismo. Entornos urbanos sostenibles: 60 proyectos Barcelona, Gustavo Gili, 192 págs

SAINZ GUTIÉRREZ, V. (2006): El proyecto urbano en España: génesis y desarrollo de un urbanismo de los arquitectos. Universidad de Sevilla.
TERÁN, F. de (1978): Planeamiento Urbano en la España Contemporánea. Historia de un proceso imposible Ed. Gustavo Gili.

- (1999): Historia del Urbanismo en España, siglos XIX y XX. Ed. Catedra.

- (2017): Antes de salir por la puerta del tiempo. Visión personal de un urbanismo real. Editorial lampreave.

Valenzuela, M. (2009): "Ciudad y sostenibilidad el mayor reto urbano del siglo XXI". Lurralde. inves. espac. 32 (2009), p. 404-436; ISSN: 0211-5891. 